\title{
Heterogeneous base catalysts for edible palm and non-edible Jatropha-based biodiesel production
}

\author{
Hwei Voon Lee ${ }^{1 *}$, Joon Ching Juan', Nurul Fitriyah Binti Abdullah², Rabiah Nizah MF² and Yun Hin Taufiq-Yap ${ }^{2 *}$
}

\begin{abstract}
Background: Transesterification catalyzed by solid base catalyst is a brilliant technology for the noble process featuring the fast reaction under mild reacting condition in biodiesel production. Heterogeneous base catalysts are generally more reactive than solid acid catalysts which require extreme operating condition for high conversion and biodiesel yield. In the present study, synthesis of biodiesel was studied by using edible (palm) or non-edible (Jatropha) feedstock catalyzed by heterogeneous base catalysts such as supported alkali metal $\left(\mathrm{NaOH} / \mathrm{Al}_{2} \mathrm{O}_{3}\right)$, alkaline-earth metal oxide ( $\mathrm{MgO}, \mathrm{CaO}$ and $\mathrm{SrO})$ and mixed metal oxides catalysts ( $\mathrm{CaMgO}$ and $\mathrm{CaZnO})$.

Results: The chemical characteristic, textural properties, basicity profile and leaching test of synthesized catalysts were studied by using X-ray diffraction, BET measurement, TPD-CO 2 and ICP-AES analysis, respectively. Transesterification activity of solid base catalysts showed that $>90 \%$ of palm biodiesel and $>80 \%$ of Jatropha biodiesel yield under $3 \mathrm{wt} . \%$ of catalyst, $3 \mathrm{~h}$ reaction time, methanol to oil ratio of $15: 1$ under $65^{\circ} \mathrm{C}$. This indicated that other than physicochemical characteristic of catalysts; different types of natural oil greatly influence the catalytic reaction due to the presence of free fatty acids (FFAs).

Conclusions: Among the solid base catalysts, calcium based mixed metal oxides catalysts with binary metal system ( $\mathrm{CaMgO}$ and $\mathrm{CaZnO}$ ) showed capability to maintain the transesterification activity for 3 continuous runs at $~ 80 \%$ yield. These catalysts render high durability characteristic in transesterification with low active metal leaching for several cycles.
\end{abstract}

Keywords: Transesterification, Palm oil, Jatropha oil, Solid base catalyst, Alkaline-earth metal oxide, Mixed metal oxides

\section{Background}

Industrialization processes continue to grow globally in par with human population which leads to the growing worldwide demand for energy as well as for petrochemical resources, coal and natural gases. This phenomenon has caused the depletion rate of fossil energy resources to increase exponentially and caused alarming environmental problems to the society. Recently, many fuel developers have showed interests in alternative renewable fuels to substitute or blend with petroleum-based fuels. An alternative fuel shall be easily available, environment friendly and techno-economically competitive [1,2].

Biodiesel plays a major role in energy sector due to its similar combustion properties with petroleum. Furthermore, biodiesel is sometimes more superior than petroleum

\footnotetext{
*Correspondence: leehweivoon@um.edu.my; taufiq@upm.edu.my ${ }^{1}$ Nanotechnology \& Catalysis Research Centre (NanoCat), Institute of Postgraduate Studies, University Malaya, 50603 Kuala Lumpur, Malaysia ${ }^{2}$ Catalysis Science and Technology Research Centre, Faculty of Science, Universiti Putra Malaysia, 43400 UPM Serdang, Selangor, Malaysia
}

diesel with improved physical and chemical properties, such as higher flash point, higher cetane number, ultralow sulfur content, better lubricity, improved biodegradability, and smaller carbon footprint [3-5]. Chemically, biodiesel is a mixture of methyl esters with long-chain fatty acids and is typically made from transesterification reaction of biological triglyceride sources such as vegetable oil and animal fats with alcohol in the presence of catalyst. This process reduces the viscosity to a value comparable to that of diesel and hence improves combustion [6].

According to Meng et al. (2009), biological feedstock supply for biodiesel production covers more than $75 \%$ of the overall production cost [7]. The favorable properties in selecting the best biodiesel feedstock include lowest oil price, high oil content, favorable fatty acid composition (saturated or unsaturated acid), low cultivation maintenance and costs, controllable growth and harvesting season, consistent seeds maturity rates and potential market for agricultural by-products [8]. 
In general, biodiesel feedstock can be divided into 4 main categories which are: (a) edible vegetable oil, (b) non-edible vegetable oil, (c) waste or recycled oil and (d) animal fats [9]. The most common feedstock employed in biodiesel production is edible and inedible oil from oleaginous plants grown in different regions. Soybean oil, sunflower oil, rapeseed oil and palm oil have been used as edible feedstock in biodiesel synthesis [10]. In Malaysia, biodiesel production is synonymous to palm oil as oil palm plantations possesses higher productivity per hectare of oil palm with lowest oil production cost per unit as compared to other vegetable oils like rapeseed and soybean [11,12]. A hectare of oilpalm plantation produces approximately 3.62 tonnes/ha/ year of oil, 5-9 times higher than other oil producing crops like soybean, sunflower and rapeseed, which produces 0.4 , 0.46 and 0.68 tonnes/ha/year, respectively [13]. This keeps the price of palm-based biodiesel competitive enough to meet the demand of commodity market $[9,14]$.

Instead of edible palm oil, non-edible feedstock is getting interest as a biodiesel feedstock in biodiesel production. Amongst the varieties of non-edible plant oil, Jatropha is the most favorable for biodiesel production as they meet the major requirement of biodiesel standards of USA, Germany and European Standard Organization. Jatropha crops can be well adapted to arid and semiarid conditions like non-cropped marginal lands and waste lands with harsh environments. Hence, the cultivation cost is lower as these crops can still sustain reasonably high yield without intensive care. Besides, Jatropha oil possesses similar composition as other vegetable oil, which favors biodiesel production. In addition, Jatropha oil contains of toxic phorbol ester which is unsuitable for human consumption and thus reduces the competitive with food supply market $[15,16]$.

A new type of heterogeneous catalysis technology has been developed to adapt the natural characteristics of biodiesel feedstock and existing transesterification technology. Utilization of heterogeneous catalyst for biodiesel production has offered some relief to biodiesel producers by improving their ability to process alternative and cheaper feedstock with simplified processes and cheaper manufacturing processes with prolonged catalyst lifetime. The three factors namely catalytic activity, catalyst life and oil flexibility have tremendous impact on the cost of biodiesel $[3,17]$. According to some research studies, the heterogeneous catalysts used for palm-based and Jatropha-based biodiesel productions are mainly from solid base catalysts e.g. alkali metal supported catalyst, hydrotalcite, alkaline-earth metal oxides, mixed metal oxides and natural waste shell, which render high transesterification activity with $>80 \%$ of biodiesel yield. It was realized that the main criteria to catalyze transesterification of these biodiesel feedstock with base catalysts is low FFA $<3$ wt.\% and moisture 1 wt.\% in the feedstock to avoid from unfavorable side reaction such as oil hydrolysis and saponification [18-27]. The formation of soap was observed in base catalyzed transesterification of high acid oil with low biodiesel yield.

By drawing on this, an attempt has been made in the present work to produce biodiesel from edible (palm) and non-edible (Jatropha) oils using heterogeneous base catalysts: (a) supported alkali metal catalysts- sodium hydroxide supported with alumina $\left(\mathrm{NaOH} / \mathrm{Al}_{2} \mathrm{O}_{3}\right),(\mathrm{b})$ alkaline-earth metal oxides- magnesium oxide $(\mathrm{MgO})$, calcium oxide $(\mathrm{CaO})$ and strontium oxide $(\mathrm{SrO})$ and $(\mathrm{c})$ calcium-based mixed metal oxides- $(\mathrm{CaMgO}$ and $\mathrm{CaZnO}$ ). This study was aimed to investigate the versatility of solid base catalysts with different chemical characteristic for transesterification of edible and non-edible biodiesel feedstock. The physicochemical properties (chemical composition, textural properties and basicity) of synthesized solid base catalysts produced thru wet impregnation and co-precipitation techniques were investigated. Furthermore, effects of the catalyst loading and reaction time towards catalyst activity were investigated in order to optimize transesterification conditions. The reusability of the solid catalysts was evaluated by batch experiment and the reasons for the deactivation of the catalyst were also discussed by performed the catalyst leaching test.

\section{Results and discussion}

\section{Catalysts characterization}

The crystalline structure of alumina supported alkali metal $\left(\mathrm{NaOH} / \mathrm{Al}_{2} \mathrm{O}_{3}\right)$, alkaline-earth metal oxide $(\mathrm{CaO}$, $\mathrm{MgO}, \mathrm{SrO}$ ) and calcium-based mixed metal oxides (CaMgO and $\mathrm{CaZnO}$ ) base solid catalysts was revealed by X-ray diffraction pattern (Figure 1). The diffraction peaks of $\mathrm{NaOH} / \mathrm{Al}_{2} \mathrm{O}_{3}$ showed the presence of $\mathrm{NaOH}$ (JCPDS File No. 27-0711) and sodium aluminate $\left(\mathrm{NaAlO}_{2}\right)$ phases (JCPDS File No. 20-1073). The intensity of $\mathrm{Al}_{2} \mathrm{O}_{3}$ peaks were reduced when $\mathrm{NaOH}$ was introduced into $\mathrm{Al}_{2} \mathrm{O}_{3}$ support, this is due to well dispersion of $\mathrm{NaOH}$ on the $\mathrm{Al}_{2} \mathrm{O}_{3}$ support in the form of monolayer covering the surface of support. The results indicate that $\mathrm{NaOH}$ has reacted with $\mathrm{Al}_{2} \mathrm{O}_{3}$ thus giving rise to the formation of aluminates and is in good agreement with that reported by Arzamendi's and Kim's research groups $[28,29]$. The diffractogram of $\mathrm{MgO}$ clearly showed that the presence of oxide phases at $2 \theta$ of 42.9 and $62.2^{\circ}$ (JCPDS File No. 4-0829). For $\mathrm{CaO}$, the diffraction pattern depicted intensified peaks at $2 \theta$ angles of $32.2,37.3$ and $53.8^{\circ}$ (JCPDS File No. 37-1497). SrO catalyst showed main reflection peaks at $2 \theta=30.31$, $50.54^{\circ}$ and $63.04^{\circ}$ (JCPDS File No. 1-074-1227). And the other peaks observed indicated the presence of $\mathrm{SrCO}_{3}$ and $\mathrm{SrO} .2 \mathrm{H}_{2} \mathrm{O}$ phases (JCPDS File No. 1-084-1778 and 28-1222). Strontium compound is difficult to regenerate 


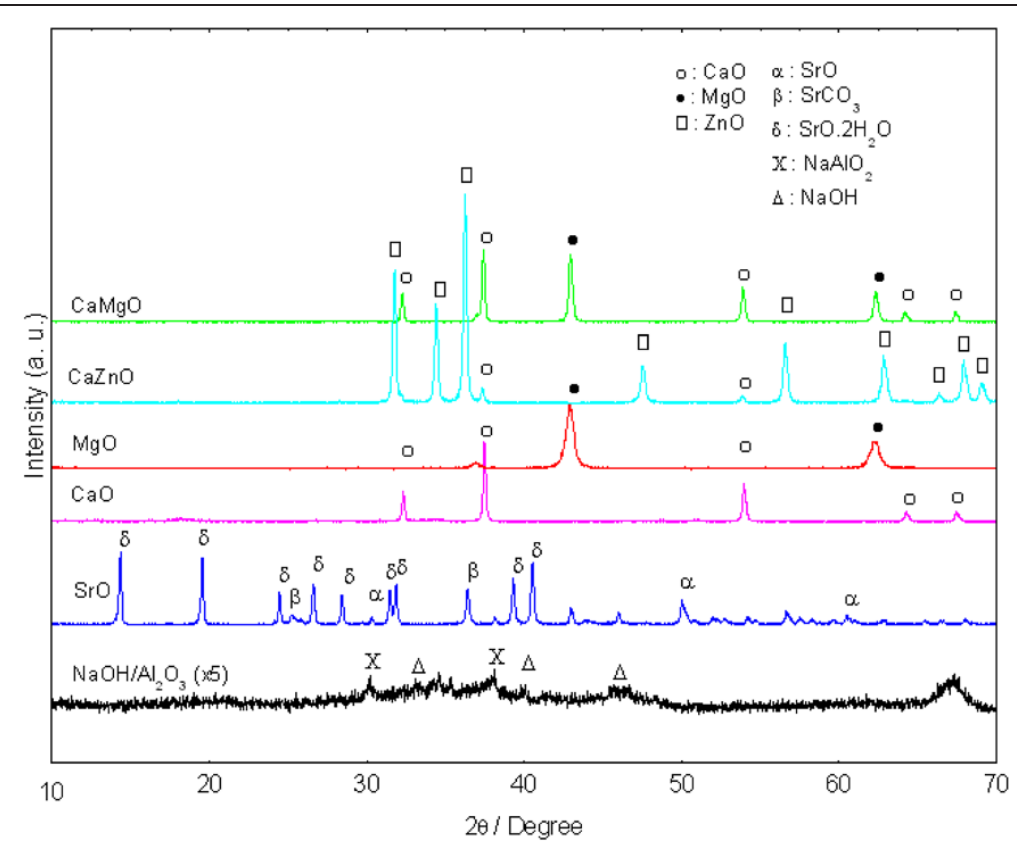

Figure 1 XRD diffractogram of synthesized solid base catalysts.

by thermal treatment, and their decomposition temperatures are higher than $1200^{\circ} \mathrm{C}$ [30]. Comparing to $\mathrm{MgO}$ and $\mathrm{CaO}, \mathrm{SrO}$ can be easily absorbed by $\mathrm{CO}_{2}$ and hydrolyzed by moisture to form carbonate and hydroxide phase, respectively which compatible with the XRD result. The XRD patterns of calcium-based mixed metal oxides catalysts recorded the patterns of both samples ( $\mathrm{CaMgO}$ and $\mathrm{CaZnO}$ ) were corresponded to pure oxide, and no new crystalline phase attributable to the formation of mixed oxides could be detected. $\mathrm{CaMgO}$ catalyst showed the appearance of cubic $\mathrm{CaO}$ and hexagonal $\mathrm{MgO}$ phases where $\mathrm{CaZnO}$ catalyst also gave diffraction peaks of $\mathrm{CaO}$ and wurzite structure of $\mathrm{ZnO}$ phase at $2 \theta$ angles of $31.7^{\circ}, 34.4^{\circ}$ and $36.2^{\circ}$ (JCPDS File No. 361451).
The textural properties of the solid base catalysts with various calcination temperatures were determined by BET measurement (Table 1). Results showed that BET surface area of pure $\gamma-\mathrm{Al}_{2} \mathrm{O}_{3}$ is $136 \mathrm{~m}^{2} / \mathrm{g}$. However, the surface area of the $\mathrm{NaOH} / \gamma-\mathrm{Al}_{2} \mathrm{O}_{3}$ catalyst was decreased to $52 \mathrm{~m}^{2} / \mathrm{g}$ after $\mathrm{NaOH}$ impregnation and thermal activation. This reflects a significant reduction of pore volume of $\mathrm{Al}_{2} \mathrm{O}_{3}$ penetrated by $\mathrm{Na}^{+}$ion as shown in Table 1 [28]. The surface area and porosity of alkaline-earth metal oxide: $\mathrm{MgO}, \mathrm{CaO}$ and $\mathrm{SrO}$ catalysts vary with different thermal activation temperature of 600,800 and $1200^{\circ} \mathrm{C}$, respectively. Calcination at high temperature is required to thermally activate the metal carbonate salts to active metal oxide catalyst for transesterification reaction, especially for $\mathrm{SrO}$ catalyst which $>1000^{\circ} \mathrm{C}$ of heating is required to remove the strong

Table 1 Surface area profile of synthesized base catalysts

\begin{tabular}{|c|c|c|c|c|}
\hline Synthesized catalyst & Calcination temperature $\left({ }^{\circ} \mathrm{C}\right)$ & BET area $\left(\mathrm{m}^{2} / \mathrm{g}\right)$ & Pore volume $\left(\mathrm{cm}^{3} / \mathrm{g}\right)$ & Pore diameter $(\AA ̊)$ \\
\hline \multicolumn{5}{|c|}{ Alkali supported alumina } \\
\hline $\mathrm{Al}_{2} \mathrm{O}_{3}$ & - & 136 & 0.436 & 132.6 \\
\hline $\mathrm{NaOH} / \mathrm{Al}_{2} \mathrm{O}_{3}$ & 500 & 52 & 0.235 & 139.1 \\
\hline \multicolumn{5}{|c|}{ Alkaline-earth metal oxide } \\
\hline $\mathrm{MgO}$ & 600 & 29.7 & 0.132 & 160.5 \\
\hline $\mathrm{CaO}$ & 800 & 9.5 & 0.072 & 213.6 \\
\hline $\mathrm{SrO}$ & 1200 & 1.0 & 0.005 & 216.0 \\
\hline \multicolumn{5}{|c|}{ Calcium-based mixed metal oxides } \\
\hline $\mathrm{CaMgO}$ & 800 & 15.5 & 0.103 & 225.3 \\
\hline $\mathrm{CaZnO}$ & 800 & 9.8 & 0.098 & 220.4 \\
\hline
\end{tabular}


bonding of carbonate from the catalyst's surface. The surface area and pore volume for $\mathrm{MgO}, \mathrm{CaO}$ and $\mathrm{SrO}$ were decreased as the calcination temperature increased, whereby the pore diameter were increased with temperature as the pore structure collapsed with high temperature. For calcium-based mixed oxides catalysts: $\mathrm{CaMgO}$ and $\mathrm{CaZnO}$, the textural properties are apparently small when synthesized using coprecipitation method. The precursor of binary metal-based catalyst in carbonate form required high temperature $\left(800^{\circ} \mathrm{C}\right)$ to render pure active mixed oxide phase for reaction which led to sintering effect of catalysts.

Several studies have reported that basicity of catalyst is the major key to improve the transesterification activity. Among basicity distribution strength (weak, medium and strong basic strength), the number of strong basic sites that are considered to be the main parameter in yielding a high biodiesel yield [31]. The total basicity and basic site distributions of synthesized solid base catalysts were measured by temperature programmed desorption of $\mathrm{CO}_{2}$ (Table 2 and Figure 2). Figure 2 showed the different desorption peaks of catalysts, which indicated the presence of basic sites with different basic strengths. The $\mathrm{CO}_{2}$ desorption band at $100-500^{\circ} \mathrm{C}$ are assigned as interaction of $\mathrm{CO}_{2}$ with sites of weak and medium basic strengths. Whereas, the $\mathrm{CO}_{2}$ desorbed at temperature of $\sim 600^{\circ} \mathrm{C}$ can be attributed to the much stronger basic site corresponding to unbounded $\mathrm{O}^{2-}$ anions [32,33]. The results showed that calcium-based mixed metal oxides $(\mathrm{CaMgO}$ and $\mathrm{CaZnO})$ and alkali supported alumina $\left(\mathrm{NaOH} / \mathrm{Al}_{2} \mathrm{O}_{3}\right)$ possess similar number of basic sites $\left(\sim 400 \mu \mathrm{mol}\right.$ of $\left.\mathrm{CO}_{2} / \mathrm{g}\right)$. This indicated that catalyst with multi-metal ion interaction showed synergy effect by enhancing the basicity on active site of catalyst [34]. However, the basicity of single metal oxide catalysts $(\mathrm{MgO}$, $\mathrm{CaO}$ and $\mathrm{SrO}$ ) were lower than binary metal catalyst as absence of combination base properties between two base metal oxides. From the results, $\mathrm{SrO}$ showed highest amount of basicity albeit lower amount of surface area than $\mathrm{MgO}$ and $\mathrm{CaO}$. This is in agreement with Hattori's theory which stated that increase of basic characteristic of oxide when going down Group II elements $(\mathrm{Mg}, \mathrm{Ca}$ and $\mathrm{Sr}$ metal cation) [35]. In addition, the surface area of Group II oxides were in reverse sequence with basicity order, this implies that surface area is not as main key to promoting the basicity and transesterification rate [36]. The TPD- $\mathrm{CO}_{2}$ profile of $\mathrm{CaO}$ showed the desorption peak at $615^{\circ} \mathrm{C}$, which slightly higher compared to the desorption temperature of calcium-based mixed metal oxides catalyst means $\left(\sim 570^{\circ} \mathrm{C}\right)$. This could be explained that higher temperature of heating is required to desorb the strong interaction of $\mathrm{CO}_{2}$ from the active basic sites of $\mathrm{CaO}$. The presence of strong basic strength in single $\mathrm{CaO}$ or binary system of calcium-based catalyst formed strong bonding with acidic $\mathrm{CO}_{2}$, and thus higher temperature (minimum $>500^{\circ} \mathrm{C}$ ) require for desorption process. From Table 2, although both $\mathrm{CaO}$ and Calciumbased catalyst render strong basic strength, the binary metal oxide provide higher amount of strong basic active sites as compared to $\mathrm{CaO}$ catalyst.

\section{Transesterification of edible palm and non-edible Jatropha oils}

The transesterification of edible (palm) and non-edible (Jatropha) oils in the presence of different solid base catalysts $\left(\mathrm{NaOH} / \mathrm{Al}_{2} \mathrm{O}_{3}, \mathrm{MgO}, \mathrm{CaO}, \mathrm{SrO}, \mathrm{CaMgO}\right.$ and $\mathrm{CaZnO}$ ) were studied thoroughly by varying the transesterification conditions. The transesterification reaction was performed at different reaction time (2-6 h) and catalyst amount (1-5 wt.\%) under constant reflux temperature $\left(65^{\circ} \mathrm{C}\right)$ and methanol to oil ratio of $15: 1$.

The catalyst amount is a crucial factor to improve the rate of transesterification reaction. As reported by most of the studies, the increase of catalyst loading shall increase surface active sites of catalyst. This indirectly improves transesterification process by increase the accessibility of triglyceride and methanol to the catalyst surface. Other than that, reaction time for transesterification is another

Table 2 TPD- $\mathrm{CO}_{2}$ profile of synthesized base catalysts

\begin{tabular}{|c|c|c|c|c|}
\hline \multirow[b]{2}{*}{ Catalyst } & \multicolumn{3}{|c|}{ Amount of basic site $\left(\mu \mathrm{mol}\right.$ of $\left.\mathrm{CO}_{2} / \mathrm{g}\right)$} & \multirow{2}{*}{$\begin{array}{c}\text { Total basicity } \\
\left(\mu \mathrm{mol} \text { of } \mathrm{CO}_{2} / \mathrm{g}\right)\end{array}$} \\
\hline & $\mathrm{T}_{\max }\left(<300^{\circ} \mathrm{C}\right)$ & $\mathrm{T}_{\max }\left(300-500^{\circ} \mathrm{C}\right)$ & $\mathrm{T}_{\max }\left(>500^{\circ} \mathrm{C}\right)$ & \\
\hline \multicolumn{5}{|c|}{ Alkali supported alumina } \\
\hline $\mathrm{NaOH} / \mathrm{Al}_{2} \mathrm{O}_{3}$ & - & - & 467.68 & 467.68 \\
\hline \multicolumn{5}{|c|}{ Alkaline-earth metal oxide } \\
\hline $\mathrm{MgO}$ & 31.36 & - & 18.95 & 50.31 \\
\hline $\mathrm{CaO}$ & - & - & 290.42 & 290.42 \\
\hline $\mathrm{SrO}$ & - & - & 396.56 & 396.56 \\
\hline \multicolumn{5}{|c|}{ Calcium-based mixed oxide } \\
\hline $\mathrm{CaMgO}$ & 2.68 & - & 449.70 & 452.38 \\
\hline CaZnO & - & - & 412.70 & 412.70 \\
\hline
\end{tabular}




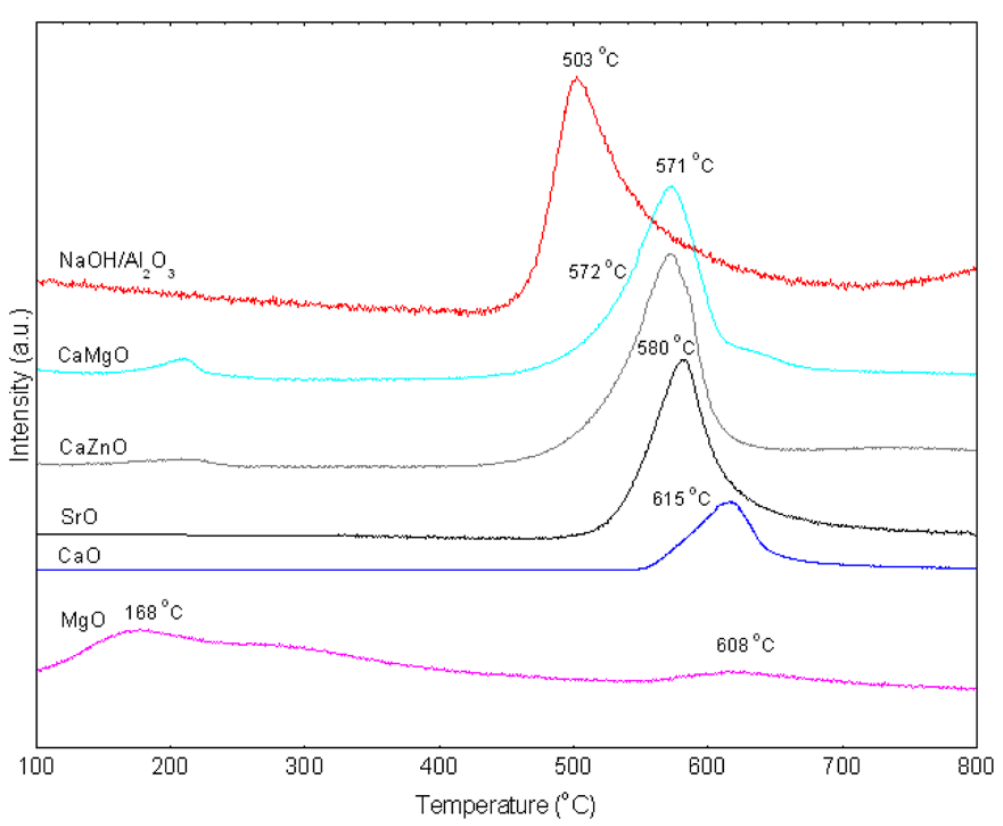

Figure $2 \mathrm{TPD}-\mathrm{CO}_{2}$ spectra of synthesized solid base catalysts.

important criterion to determine the equilibrium point of reaction in order to avoid any reverse process [6,37]. The biodiesel profile revealed that edible palm oil underwent transesterification relatively at a higher reaction rate compared to the non-edible Jatropha oil. Results showed that the transesterification of palm oil yielded more than $90 \%$ of biodiesel under mild condition of $3 \mathrm{wt} . \%$ catalyst, $3 \mathrm{~h}$ reaction time and 15:1 methanol/oil molar ratio. Jatropha biodiesel production required higher amount of catalyst (4 wt.\%) (Figure 3) and longer reaction time $(4 \mathrm{~h})$ (Figure 4$)$ in order to improve the biodiesel yield to more than $80 \%$ compared to palm biodiesel.

The present study imply that the nature of edible and non-edible oil significantly influence the transesterification activity of catalysts [38]. Although non-edible Jatropha oil has tremendous potential for biodiesel production but it contains high free fatty acids (FFAs) as compared to palm oil. The FFAs content is key parameter for determining the

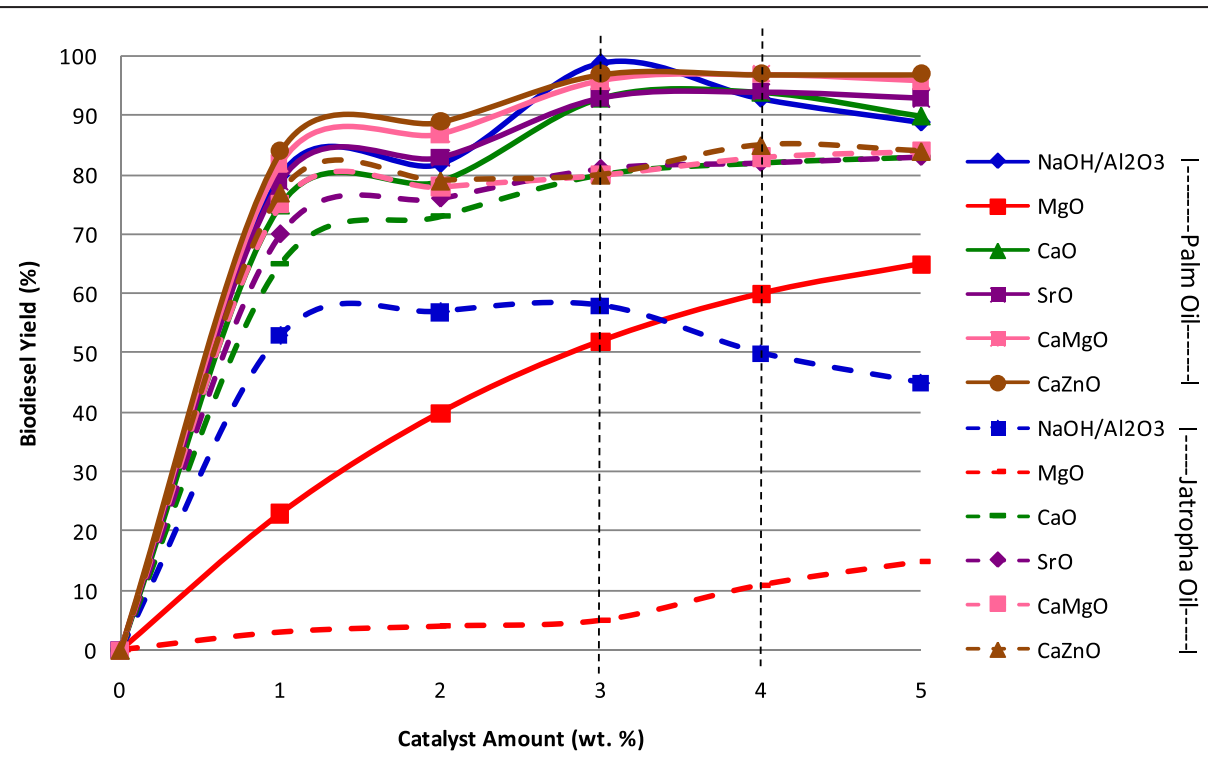

Figure 3 Effect of catalyst amount for solid base catalyzed transesterification reaction of palm and Jatropha oil (methanol: oil ratio of $15: 1,65^{\circ} \mathrm{C}$ and $3 \mathrm{~h}$ ). 


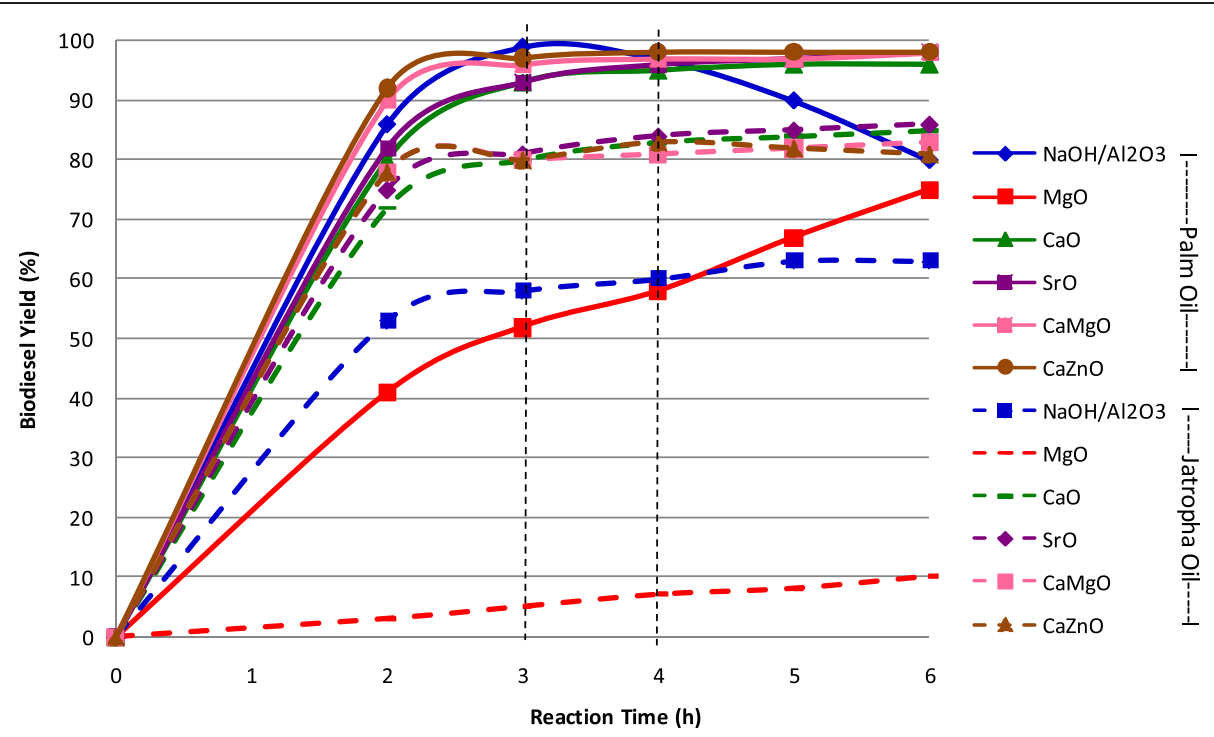

Figure 4 Effect of reaction time for solid base catalyzed transesterification reaction of palm and Jatropha oil (methanol: oil ratio 15:1, $\left.65^{\circ} \mathrm{C}, 3 \mathrm{wt} . \%\right)$.

viability of the vegetable oil in transesterification process. Higher FFAs content of the oil will lower the biodiesel selectivity. This happened to $\mathrm{NaOH} / \mathrm{Al}_{2} \mathrm{O}_{3}$ catalyzed transesterification of high acid Jatropha oil. Jatropha biodiesel yield is $58 \%$, while the low acid palm oil achieved conversion of 99\% (Figure 5). The presence of FFAs in Jatropha oil triggered saponification with sodium base catalyst resulting soap formation which could lead to formation of gel and emulsion. This is highly undesirable and complicates the purification process of biodiesel [10]. The $\mathrm{NaOH} / \mathrm{Al}_{2} \mathrm{O}_{3}$ was deactivated as the active sodium was loss to formation of soap and in turn reduced transesterification activity.
FFAs content directly influences biodiesel yield in biodiesel production.

Other than oil characteristics, the rate of transesterification is greatly depending on catalyst's basicity. Among the solid base catalysts, the catalytic activity of $\mathrm{MgO}$ for both palm and Jatropha-based transesterification are low, which is $52 \%$ and $5 \%$, respectively. The results suggested that, under reflux condition, the optimum content of biodiesel synthesis using edible and non-edible oil greatly depend on the type of the solid base catalyst used. According to $\mathrm{Di}$ Serio and his co-researcher [33], basicity of catalyst is directly proportional to the biodiesel yield. $\mathrm{MgO}$ catalyst with

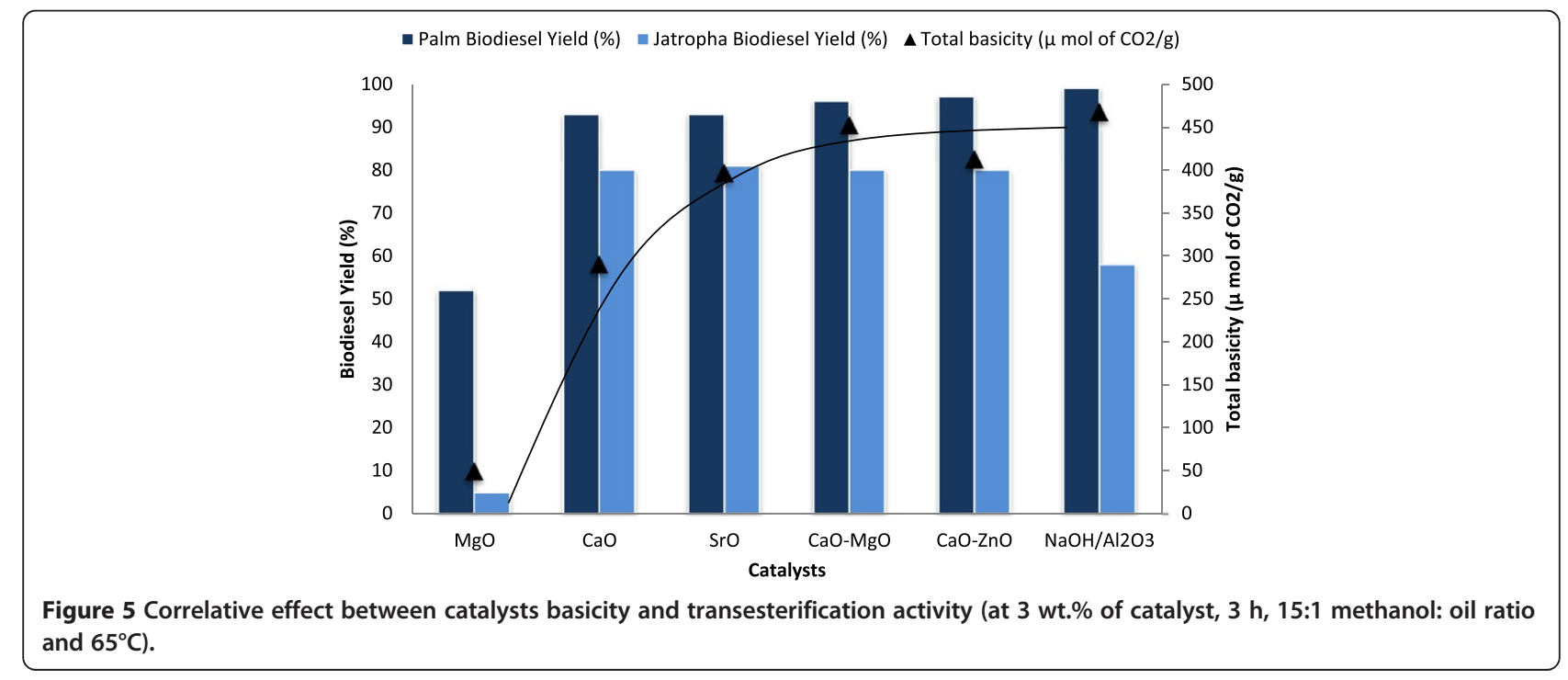


lower amount of basicity is less active than other catalysts by producing less yield of biodiesel under mild condition. This fact has been proven by the correlation effect between transesterification activities and basicity of different catalysts (Figure 5).

\section{Durability of catalyst}

Under optimized conditions (reaction temperature of $65^{\circ} \mathrm{C}, 3.0 \mathrm{wt} . \%$ of catalyst, $15: 1$ methanol/oil molar ratio and $3 \mathrm{~h}$ reaction time), the solid base catalysts $(\mathrm{NaOH} /$ $\mathrm{Al}_{2} \mathrm{O}_{3}, \mathrm{CaO}, \mathrm{SrO}, \mathrm{CaMgO}$ and $\mathrm{CaZnO}$ ) were reutilized for another two runs for both edible palm and nonedible Jatropha oil (Figure 6). Among these catalysts, $\mathrm{CaMgO}$ and $\mathrm{CaZnO}$ demonstrated high reusability. However, $\mathrm{MgO}$ catalyst was not selected for the reusability test as it is low in catalytic activity. Surprisingly, only calcium based mixed metal oxides catalysts are capable to maintain high yield $>80 \%$ of palm-biodiesel and $>70 \%$ of Jatropha-biodiesel at third run. From the results, $\mathrm{NaOH} / \mathrm{Al}_{2} \mathrm{O}_{3}$ catalyzed reaction drop drastically throughout the three runs. This apparently demonstrated that the catalyst was unstable during reaction in which $\mathrm{Na}-\mathrm{O}-\mathrm{Al}$ was decomposed in the present of methanol in the first run reaction medium. Therefore, the catalytic activities of second and third runs were reduced as the active $\mathrm{Na}$ species was reduced. For alkaline-earth metal oxides catalysts, the catalytic activities were reduced gradually in every cycle. The metal oxides are poisoned by absorption of $\mathrm{H}_{2} \mathrm{O}, \mathrm{CO}_{2}$ and reaction medium (e.g. glycerol, oil, methyl ester). Extra washing step and thermal activation is required prior to each cycle to maintain high reusability. In order to evaluate the leaching of the catalyst, elemental analysis was performed to study the leaching of $\mathrm{Ca}, \mathrm{Mg}$ and $\mathrm{Zn}$ phases for $\mathrm{CaMgO}$ and $\mathrm{CaZnO}$ catalysts. The result for the fresh and used catalyst was depicted in Table 3. It is showed that the only minor amount of calcium, magnesium and zinc leached out during reaction and thus it is negligible. This result is concordance with the catalytic activity of $\mathrm{CaMgO}$ and $\mathrm{CaZnO}$ which capable of maintaining it activity after the third cycles.

\section{Experimental}

\section{Preparation of solid base catalysts}

Supported alkaline metal catalysts: $\mathrm{NaOH} / \mathrm{Al}_{2} \mathrm{O}_{3}$

The catalyst was prepared by incipient wetness impregnation of $\gamma-\mathrm{Al}_{2} \mathrm{O}_{3}$ powder with an aqueous solution of $\mathrm{NaOH}$ compounds. $\mathrm{Al}_{2} \mathrm{O}_{3}$ support was impregnated with $15 \mathrm{ml}$ sodium hydroxide (50 wt.\%) solution. The impregnate was dried in oven at $100^{\circ} \mathrm{C}$ overnight and undergone thermal treatment at $500^{\circ} \mathrm{C}$.

\section{Alkaline-earth metal oxide: $\mathrm{MgO}, \mathrm{CaO}$ and $\mathrm{SrO}$}

$\mathrm{MgO}, \mathrm{CaO}$ and $\mathrm{SrO}$ were obtained after calcination of pulverized magnesium carbonate $\left(\mathrm{MgCO}_{3}\right)$, lime stone $\left(\mathrm{CaCO}_{3}\right)$ and strontium carbonate $\left(\mathrm{SrCO}_{3}\right)$.

\section{Mixed metal oxide: CaMgO and CaZnO}

The mixed metal oxide catalysts were prepared by using co-precipitation method, and subsequent calcinations of the precursors. These catalysts were obtained by slowly adding a $2 \mathrm{M}$ aqueous solution of the corresponding metal nitrates to an aqueous solution containing

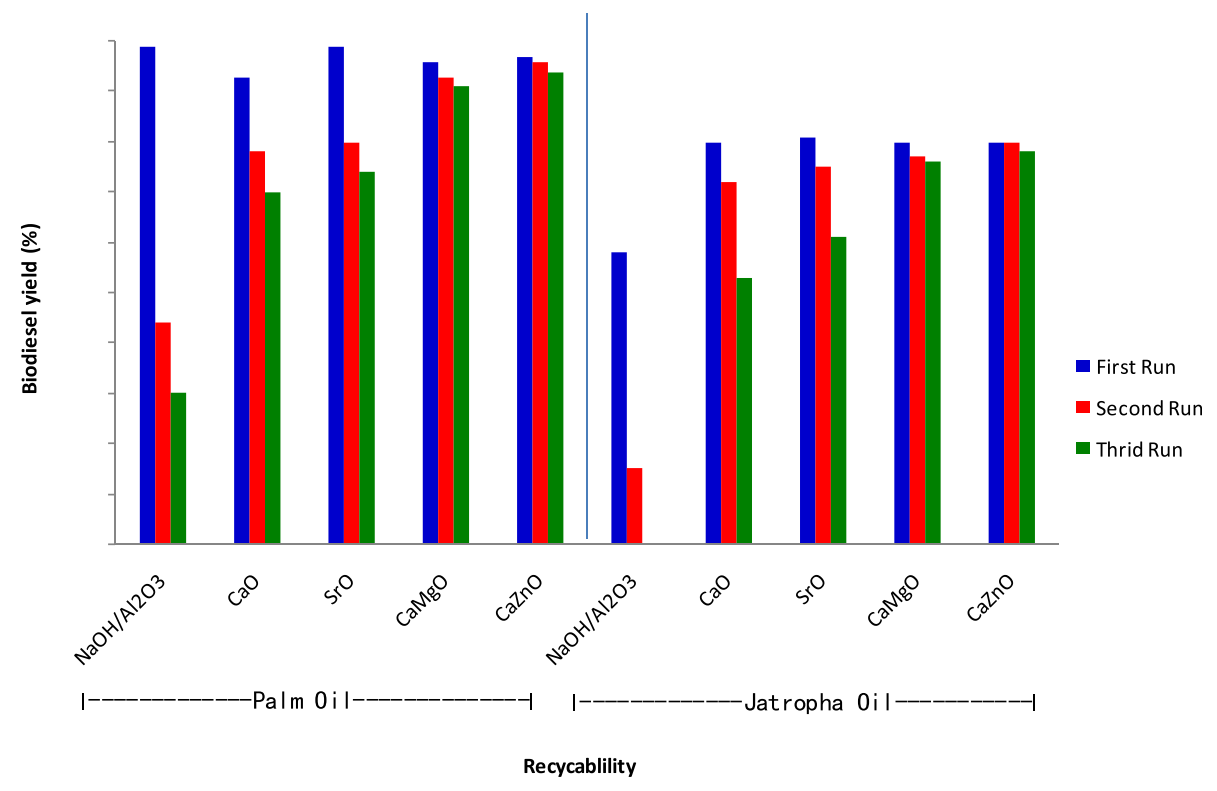

Figure 6 Reusability of solid base catalysts. 
Table 3 Leaching tests profile of CaMgO and CaZnO

\begin{tabular}{cccccc}
\hline Catalysts & \multicolumn{2}{c}{ CaMgO } & & \multicolumn{2}{c}{ CaZnO } \\
\cline { 2 - 3 } \cline { 6 - 7 } Element content $^{\text {a }}$ (ppm) & $\mathbf{C a}$ & $\mathbf{M g}$ & & $\mathbf{C a}$ & $\mathbf{Z n}$ \\
\hline Fresh catalyst & $17.9 \pm 0.5$ & $36.2 \pm 0.3$ & & $10.0 \pm 0.4$ & $74.3 \pm 0.7$ \\
3rd run ${ }^{\mathrm{b}}$ & $15.6 \pm 0.7$ & $29.8 \pm 0.2$ & & $8.6 \pm 0.3$ & $67.4 \pm 0.6$
\end{tabular}

${ }^{\mathrm{a}} \mathrm{Ca}, \mathrm{Mg}$ and $\mathrm{Zn}$ content from catalysts were determined by ICP-AES analysis. beaching experiments were conducted in triplicate to determine the content of the $\mathrm{CaMgO}$ and $\mathrm{CaZnO}$ after reaction in Jatropha oil.

$\mathrm{Na}_{2} \mathrm{CO}_{3}$ and $\mathrm{NaOH}$. The precipitation was performed under vigorous stirring at $65^{\circ} \mathrm{C}$, for 1 day. Finally, the solids were filtered, washed with deionized water and dried at $100^{\circ} \mathrm{C}$. The synthesized precursors were then undergone thermal treatment $\left(800^{\circ} \mathrm{C}\right)$ in the air to produce mixed metal oxides.

\section{Characterization}

The crystalline phases of synthesized catalysts were analyzed by powder X-ray diffraction analysis using a Shimadzu diffractometer model XRD 6000 with employing $\mathrm{Cu}-\mathrm{K}_{\alpha}$ radiation to generate diffraction patterns from powder crystalline samples at ambient temperature. Specific surface area of the catalysts was obtained by the BET (Brunauer-Emmer-Teller) method using Thermo Finnigan Sorptomatic 1900 series nitrogen adsorption/desorption analyzer. The total basicity and basic strength of the catalysts were measured by temperature programmed desorption of carbon dioxide $\left(\mathrm{CO}_{2}\right.$-TPD) using a Thermo Finnigan TPDRO 1100 apparatus provided with a thermal conductivity detector. The elemental composition of fresh and used catalysts was determined by using inductively coupled plasma-atomic emission spectrometer (ICP-AES) analysis that conducted by using Perkin Elmer Emission Spectrometer Model Plasma 1000.

\section{Catalytic test}

The biodiesel feedstock, palm oil and Jatropha oil were purchased from local market and Bionas Sdn. Bhd., respectively. Physicochemical properties of both palm and Jatropha oil were shown in Table 4. Catalytic activity was evaluated by performing transesterification reaction in a batch reflux-reactor, which palm or Jatropha oil was mixed with methanol and synthesized solid base catalyst. The mixture was added into round-bottom flask equipped with a reflux condenser and heated at $65^{\circ} \mathrm{C}$ under constant stirring speed at $800 \mathrm{rpm}$. Investigation on effect of reaction time $(2-6 \mathrm{~h})$ and catalyst amount (1-5 wt.\%) was investigated in order to achieve optimum biodiesel yield. Upon the completion of reaction, the product was cooled to ambient temperature and the catalyst was separated thru centrifugation. The excessive methanol was removed using rotary evaporator. Reaction product was then poured into a separation funnel and left overnight for separation with upper layer as
Table 4 Physicochemical properties and characteristic of palm oil and Jatropha oil

\begin{tabular}{ccc}
\hline Properties (unit) & Palm oil & Jatropha oil \\
\hline Specific gravity $\left(\mathrm{gcm}^{-3}\right)$ & $0.860-0.90$ & 0.914 \\
Viscosity at $40^{\circ} \mathrm{C}(\mathrm{cSt})$ & 44.2 & 54.8 \\
Sulphated Ash $(\%$ mass) & 0.02 & 0.0012 \\
Flash point $\left({ }^{\circ} \mathrm{C}\right)$ & 182 & 235 \\
Cloud point $\left({ }^{\circ} \mathrm{C}\right)$ & 15 & 2 \\
Pour point & 15 & 2 \\
Cetane Number & - & 46.3 \\
Saponification number (mg g & 198.9 & $186.48-193.32$ \\
Free Fatty acids\% (Kg Kg $\left.{ }^{-1} \times 100\right)$ & $<1$ & $9.0-12.0$ \\
Fatty acid composition (\%) & & \\
Palmitic acid (16:0) & 44.2 & 13.8 \\
Stearic acid (18:0) & 4.5 & 6.8 \\
Oleic acid (18:1) & 39.6 & 41.7 \\
Linoleic acid (18:2) & 9.8 & 35.6 \\
\hline
\end{tabular}

biodiesel and glycerin at the bottom layer. The biodiesel product was analyzed by using a gas chromatography (PerkinElmer Autosystem XL, USA) equipped with a flame ionization detector (FID) and connected to a HPInnowax capillary column $(30 \mathrm{~m} \times 0.25 \mathrm{~mm} \times 0.25 \mu \mathrm{m}$; J \& W Scientific). The content of methyl ester obtained was calculated according to European regulated procedure EN14103.

\section{Conclusions}

Heterogeneous base catalysts $\left(\mathrm{NaOH} / \mathrm{Al}_{2} \mathrm{O}_{3}, \mathrm{MgO}, \mathrm{CaO}\right.$, $\mathrm{SrO}, \mathrm{CaMgO}$ and $\mathrm{CaZnO}$ ) were used as catalysts for the production of biodiesel from edible palm and non-edible Jatropha oils. All the base catalysts showed the presence of strong basic strength on the active site except for $\mathrm{MgO}$ which contained dominant amount of medium basic sites. The transesterification activity of the heterogeneous base catalysts are correlated with basicity and basic strengths of the catalysts. The optimum conditions for solid base catalysts to achieve $>90 \%$ of palm biodiesel is 3 wt.\% of catalyst, $15: 1$ of methanol to oil molar ratio within $3 \mathrm{~h}$. Jatropha biodiesel yield required higher amount of catalyst $(4$ wt.\%) and longer reaction time $(4 \mathrm{~h})$ under reflux temperature to achieve yield $>80 \%$. It is reasonable to conclude that the type of feedstock oil and chemical characteristic of solid base catalyst strongly affects the yield of biodiesel. Despite of good transesterification activity for solid base catalyst, a good candidate of basic catalyst should be able to tolerate free fatty acids and moisture content in feedstock oil. High catalyst's reusability without leaching of active component is another desirable characteristic in good candidate catalyst. Calcium-based mixed metal oxides catalysts (CaMgO 
and $\mathrm{CaZnO}$ ) render high durability characteristic in transesterification with low active metal leaching for several cycles. The strong interactions between active metals provide a superior synergism of high basicity and stability effect for transesterification reaction.

\section{Competing interests}

The authors declare that they have no competing interests.

\section{Authors' contributions}

LHV conceived of the study, participated in its design and coordination and drafted the manuscript. JJC provided advice on the testing method, analyzed results and helped to draft the manuscript. NFA and RNM performed partial experiments and analyzed results. YHTY contributed to conception and catalyst design, reaction study and provided research advice in data interpretation. All authors read and approved the manuscript.

\section{Authors' information}

First Author: Hwei Voon Lee.

Co-Authors: Joon Ching Juan, Nurul Fitriyah binti Abdullah, Rabiah Nizah MF, Yun Hin Taufiq-Yap.

\section{Acknowledgements}

The authors acknowledge the financial support of the Graduate Research Fellowship (GRF) from the Universiti Putra Malaysia and the financial support from Ministry of Higher Education Malaysia for Fundamental Research Grant Scheme (FRGS, Project Number: FP056-2013B).

Received: 27 January 2014 Accepted: 23 April 2014

Published: 3 May 2014

\section{References}

1. Abdullah AZ, Salamatinia B, Mootabadi H, Bhatia S: Current status and policies on biodiesel industry in Malaysia as the world's leading producer of palm oil. Energ Pol 2009, 37(12):5440-5448.

2. Sharma YC, Singh B, Upadhyay SN: Advancements in development and characterization of biodiesel: a review. Fuel 2008, 87(12):2355-2373.

3. Yan S, DiMaggio C, Mohan S, Kim M, Salley SO, Simon Ng KY: Advancements in heterogeneous catalysis for biodiesel synthesis. Top Catal 2010, 53:721-736.

4. Benjumea P, Agudelo J, Agudelo A: Basic properties of palm oil biodieseldiesel blends. Fuel 2008, 87(10-11):2069-2075.

5. Jha SK, Fernando S, To SDF: Flame temperature analysis of biodiesel blends and components. Fuel 2008, 87(10-11):1982-1988.

6. Leung DYC, Wu X, Leung MKH: A review on biodiesel production using catalyzed transesterification. Appl Energy 2010, 87(4):1083-1095.

7. Meng X, Yang J, Xu X, Zhang L, Nie Q, Xian M: Biodiesel production from oleaginous microorganisms. Renew Energy 2009, 34(1):1-5.

8. Bryan RM: Biodiesel production, properties and feedstocks. Vitro Cell Dev Biol Plant 2009, 45:229-266

9. Lim S, Lee KT: Recent trends, opportunities and challenges of biodiesel in Malaysia: an overview. Renew Sust Energ Rev 2010, 14(3):938-954.

10. Vasudevan PT, Fu B: Environmentally sustainable biofuels: advances in biodiesel research. Waste Biomass Valorization 2010, 1:47-63.

11. Basiron Y: The Palm Oil Advantage in Biofuel. New Straits Times. New Straits Times. 24 February 2007. Available from [http://www.mpoc.org. my/The_Palm_Oil_Advantage_In_Biofuel.aspx]

12. Wikipedia: Table of Biofuel Crop Yields. 2009.

13. Sumathi S, Chai SP, Mohamed AR: Utilization of oil palm as a source of renewable energy in Malaysia. Renew Sust Energ Rev 2008, 12(9):2404-2421

14. Sarin R, Sharma M, Sinharay S, Malhotra RK: Jatropha-palm biodiesel blends: an optimum mix for Asia. Fuel 2007, 86(10-11):1365-1371.

15. Rathore V, Madras G: Synthesis of biodiesel from edible and non-edible oils in supercritical alcohols and enzymatic synthesis in supercritical carbon dioxide. Fuel 2007, 86(17-18):2650-2659.

16. Juan JC, Kartika DA, Wu TY, Hin T-YY: Biodiesel production from jatropha oil by catalytic and non-catalytic approaches: an overview. Bioresour Technol 2011, 102(2):452-460.
17. Taufiq-Yap YH, Lee HV: Higher grade biodiesel production by using solid heterogeneous catalysts. In Advances in Biofuels. Edited by Pogaku R, Sarbatly RH. US: Springer; 2013:153-176.

18. Gao L, Teng G, Xiao G, Wei R: Biodiesel from palm oil via loading KF/Ca-Al hydrotalcite catalyst. Biomass Bioenergy 2010, 34(9):1283-1288.

19. Zabeti M, Daud WMAW, Aroua MK: Biodiesel production using alumina-supported calcium oxide: an optimization study. Fuel Process Technol 2010, 91(2):243-248.

20. Soetaredjo FE, Ayucitra A, Ismadji S, Maukar AL: $\mathrm{KOH} /$ bentonite catalysts for transesterification of palm oil to biodiesel. App/ Clay Sci 2011, 53:341-346.

21. Salamatinia B, Mootabadi H, Bhatia S, Abdullah AZ: Optimization of ultrasonic-assisted heterogeneous biodiesel production from palm oil: a response surface methodology approach. Fuel Process Technol 2010, 91(5):441-448

22. Trakarnpruk W, Porntangjitlikit S: Palm oil biodiesel synthesized with potassium loaded calcined hydrotalcite and effect of biodiesel blend on elastomer properties. Renew Energy 2008, 33(7):1558-1563.

23. Hameed BH, Lai LF, Chin LH: Production of biodiesel from palm oil (Elaeis guineensis) using heterogeneous catalyst: an optimized process. Fuel Process Technol 2009, 90(4):606-610.

24. Wan Z, Hameed BH: Transesterification of palm oil to methyl ester on activated carbon supported calcium oxide catalyst. Bioresour Technol 2011, 102(3):2659-2664.

25. Cho YB, Seo G: High activity of acid-treated quail eggshell catalysts in the transesterification of palm oil with methanol. Bioresour Technol 2010, 101 (22):8515-8519.

26. Baroutian S, Aroua MK, Raman AAA, Sulaiman NMN: Potassium hydroxide catalyst supported on palm shell activated carbon for transesterification of palm oil. Fuel Process Technol 2010, 91(11):1378-1385.

27. Viriya-empikul N, Krasae P, Puttasawat B, Yoosuk B, Chollacoop N, Faungnawakij $\mathrm{K}$ : Waste shells of mollusk and egg as biodiesel production catalysts. Bioresour Technol 2010, 101(10):3765-3767.

28. Arzamendi G, Campo I, Arguiñarena E, Sánchez M, Montes M, Gandía LM: Synthesis of biodiesel with heterogeneous $\mathrm{NaOH} /$ alumina catalysts: comparison with homogeneous NaOH. Chem Eng J 2007, 134(1-3):123-130.

29. Kim H-J, Kang B-S, Kim M-J, Park YM, Kim D-K, Lee J-S, Lee K-Y: Transesterification of vegetable oil to biodiesel using heterogeneous base catalyst. Catal Today 2004, 93-95:315-320

30. Patil PD, Deng S: Transesterification of camelina sativa oil using heterogeneous metal oxide catalysts. Energy and Fuels 2009, 23(9):4619-4624.

31. Fraile JM, García N, Mayoral JA, Pires E, Roldán L: The basicity of mixed oxides and the influence of alkaline metals: the case of transesterification reactions. App/ Catal A Gen 2010, 387(1):67-74

32. Albuquerque MCG, Santamar-Gonzez J, Mida-Robles JM, Moreno-Tost R, Rodruez-Castell E, Jimez-Lez A, Azevedo DCS, Cavalcante CL Jr, MairelesTorres P: MgM (Al and $\mathrm{Ca}$ ) oxides as basic catalysts in transesterification processes. Appl Catal A Gen 2008, 347(2):162-168.

33. Di Serio M, Ledda M, Cozzolino M, Minutillo G, Tesser R, Santacesaria E: Transesterification of soybean oil to biodiesel by using heterogeneous basic catalysts. Ind Eng Chem Res 2006, 45(9):3009-3014.

34. Lee HV, Taufiq-Yap YH, Hussein MZ, Yunus R: Transesterification of jatropha oil with methanol over Mg-Zn mixed metal oxide catalysts. Energy 2013, 49:12-18.

35. Hattori H: Solid base catalysts: generation, characterization, and catalytic behavior of basic sites. J J.jpn Petrol Inst 2004, 47(2):67-81.

36. Kouzu M, Yamanaka S-Y, Hidaka J-S, Tsunomori M: Heterogeneous catalysis of calcium oxide used for transesterification of soybean oil with refluxing methanol. Appl Catal A Gen 2009, 355(1-2):94-99.

37. Mathiyazhagan $\mathrm{M}$, Ganapathi A: Factors affecting biodiesel production. Res Plant Biol 2011, 1(2):1-5.

38. Babu NS, Sree R, Prasad PSS, Lingaiah N: Room-temperature transesterification of edible and nonedible oils using a heterogeneous strong basic Mg/La catalyst. Energy Fuels 2008, 22(3):1965-1971.

doi:10.1186/1752-153X-8-30

Cite this article as: Lee et al: Heterogeneous base catalysts for edible palm and non-edible Jatropha-based biodiesel production. Chemistry Central Journal 2014 8:30. 